\title{
CONTRIBUIÇÕES DA LITERATURA REGIONALISTA NA FORMAÇÃO DO PENSAMENTO GEOGRÁFICO NO AMAZONAS
}

\author{
Matheus Pinto de Souza \\ Universidade do Estado do Amazonas-UEA, Manaus-AM, Brasil \\ mpds.geo15@uea.edu.br \\ Isaque dos Santos Sousa \\ Universidade do Estado do Amazonas-UEA, Manaus-AM, Brasil \\ isousa@uea.edu.br \\ Susane Patrícia Melo de Lima \\ Universidade do Estado do Amazonas-UEA, Manaus, AM, Brasil \\ splima@uea.edu.br
}

\begin{abstract}
RESUMO
O presente artigo pauta-se na elucidação das bases de formação do pensamento geográfico no Amazonas, considerando a literatura regionalista do período anterior à institucionalização dos primeiros cursos de geografia no Brasil e no Amazonas. Através do método geo-histórico, levantamento e análise bibliográfica, buscou-se identificar como os textos clássicos elaborados por viajantes e exploradores que descreveram a Amazônia, registrando os eventos num determinado espaço e tempo na região, consolidaram-se como registros fundantes do pensamento geográfico no Amazonas. Evidencia-se assim, que as bases que respaldam este momento da geografia tornam-se importantes para compreender que tal ciência lança mão da relação homem-meio, sociedade-natureza, logo, adotando como pilar as dinâmicas da natureza e da sociedade, bem como os processos históricos, econômicos, políticos e territoriais, que correlacionados, embasaram a evolução do pensar e fazer geográfico, até o momento da institucionalização do primeiro curso superior de geografia no Estado do Amazonas, na década de 1980. A literatura regionalista ganha evidência ao apontar as descrições marcadas pelo empirismo e naturalismo, acerca do espaço e da espacialidade, e ainda, possibilita uma leitura de caráter geográfico que permitem o estabelecimento de balizas analíticas para este espaço-tempo.
\end{abstract}

Palavras-chave: Amazônia. Teoria e método da Geografia. Epistemologia da Geografia.

\section{CONTRIBUTIONS OF REGIONALIST LITERATURE IN THE FORMATION OF GEOGRAPHIC THOUGHT IN THE AMAZON}

\begin{abstract}
This article is guided in elucidation of the training bases of geographic thought in the Amazon, considering the regionalist literature of the period prior to the institutionalization of the first courses of geography in Brazil and in the Amazon. Through the geo-historical method, survey and bibliographic analysis, we sought to identify how the classical texts prepared by travelers and explorers who described the Amazon, registering the events in a given space and time in the region, were consolidated as he wrote records of geographic thought in the Amazon. It is evidenced that the foundations that support this time of geography becomes important to understand that such science spear hand of mankind, society-nature, adopting as the dynamics of nature and pillar of society, as well as the historical processes, economic, political and territorial, that correlated, published the evolution of thinking and do geographical by the time of the institutionalization of first degree in geography in the Stare of Amazon, in the Decade of 1980. The regionalist literature evidence to win descriptions marked by empiricism and naturalism, about space and spatiality, and also allows a reading of geographic character that allow the establishment of analytical beacons for this space-time.
\end{abstract}

Keywords: Amazon. Theory and method of Geography. Epistemology of Geography.

$\begin{array}{lllll}\text { Caminhos de Geografia } & \text { Uberlândia-MG } & \text { v. 21, n. } 77 & \text { Out/2020 } & \text { p. 253-262 }\end{array}$




\section{INTRODUÇÃO}

A Amazônia historicamente possui narrativas que valorizam seus aspectos geográficos, sobretudo aquelas de viajantes, pesquisadores, exploradores e visionários que desde a colonização da região buscaram conhecer, descrever, e/ou mesmo, apropriar-se de suas riquezas naturais.

A Amazônia selvagem sempre teve o dom de impressionar a civilização distante. Desde os primeiros tempos da colônia, as mais imponentes expedições e solenes visitas pastorais rumavam de preferência às suas plagas desconhecidas. Para lá os mais veneráveis bispos, os mais garbosos capitães-generais, os mais lúcidos cientistas (CUNHA, 2006, p. 25).

Vários trabalhos objetivaram descrever a fauna, os rios e mesmo o clima peculiar da região Amazônica, relatos estes que colaboraram significativamente para a construção do savoir faire geográfico no Amazonas.

Conhecer a história do pensamento geográfico, considerando as bases epistemológicas desta ciência quando de sua sistematização no século XIX, e posteriormente, a consolidação da mesma no Brasil, que depois se espraia chegando a institucionalizar-se também no Amazonas, mostra-se de extrema importância para compreensão dos rumos que a ciência geográfica tomou até a sua consolidação no ensino superior, sendo este o alvo desta pesquisa.

A busca pela elucidação do processo de construção e mesmo de materialização do pensamento geográfico no Amazonas fundamenta-se, desta forma, nos primeiros relatos sobre a região onde foi possível identificar, além da riqueza na descrição dos aspectos físicos e características naturais, uma forte crítica ao modo de vida do homem amazônico, sobretudo nos escritos de Euclides da Cunha (2006). Outro questionamento diz respeito ao próprio título de "homem preguiçoso" inferido por autores deterministas que discorreram sobre a Amazônia, desprezando "o incoercível da fatalidade física, aquela natureza soberana e brutal, em pleno expandir das suas energias, é uma adversária do homem" (CUNHA, 2006, p. 27), bem como da exploração dos grupos nativos no período colonial e dos imigrantes nos tempos áureos da borracha (CUNHA, 2006), também discutido por Márcio Souza (2003). Soma-se a estas questões o abandono pelo qual a região amazônica passou por todo século XIX (BATISTA, 2007).

A já conhecida luta do homem amazônico por coexistir junto a floresta destaca-se visto que, ocupar os confins da Amazônia, com cenários inóspitos e distâncias penosas, assim descritas por Alberto Rangel (2017), foi um desafio enfrentado pelos que persistiram em ocupar esta porção do território brasileiro, haja vista suas particularidades físicas.

Entende-se desta forma tratar-se de um pensamento fundamentado na relação sociedade-natureza, apontando para uma dinâmica da natureza e da própria sociedade que se estabelece através de um vínculo de interdependência, onde um influencia e é influenciado pelo outro tendo como resultado as construções materiais e imateriais que subordinam as dinâmicas e relações políticas, econômicas e sociais.

Destarte, busca-se também ater-se aos períodos históricos (político e econômico) pelos quais a Amazônia passara, a fim de observar os processos sociais em cada uma dessas escalas e momentos, tal qual sua importância para o entendimento da relação sociedade-natureza, não podendo assim ser vista de forma disjunta.

Por fim, objetiva-se apresentar as bases do pensamento geográfico no Amazonas, do desenvolvimento de seus postulados e construção metodológica até sua institucionalização como curso para formação superior no Amazonas, efetuada na década de 1980.

\section{METODOLOGIA}

Através da análise geo-histórica do levantamento e análise bibliográfica e documental, buscou-se elencar os principais escritos de cunho geográfico e recuperar autores importantes para a evolução do pensamento geográfico no Amazonas, identificando as bases epistemológicas da geografia no Amazonas.

Recorrer a análise geo-histórica justifica-se pelo fato de que, segundo Braudel (1995), a ideia central é a de reconstituir para explicar o fenômeno, ou seja, a reconstrução, resgate dos processos e fenômenos sociais, compõe o meio, já a explicação é posta como sendo o fim, ou seja, considerar a 
ligação espaço-temporal, representada pela relação natureza/homem/natureza, cristalizada nos escritos da época anterior à institucionalização do primeiro curso de geografia no Amazonas, na década de 1980, torna-se importante, pois possibilita estabelecer como os processos sociais associam-se aos momentos históricos da região e como estes "pontos" na história influenciaram no desenvolvimento regional, identificando, desta forma, de que maneira as pesquisas e observações da época contribuíram para a consolidação do pensamento geográfico no Amazonas.

O encadeamento proposto entre Geografia e História, como ferramenta para compreender os processos sociais, territoriais, políticos, culturais, proposto por Braudel (1999) de forma a localizar cada evento em um determinado espaço/tempo, está para além da mera combinação de conceitos e métodos distintos.

Para Ribeiro (2015) o método historiográfico

não é apenas a fusão de duas tradições, mas seu aperfeiçoamento em uma tessitura cuidadosamente equilibrada. Trata-se de ferramenta capaz de perscrutar como o meio ambiente e o espaço construído integraram o processo histórico de longa duração que transformou a superfície terrestre em ecúmeno - o que significa escavar seus efeitos na composição da vida social (RIBEIRO, 2015, p. 608).

A concepção de Geo-história, defendida por Ribeiro (2015), pauta-se no entendimento das relações do homem e do meio, das paisagens naturais e culturais dispostas nos grandes territórios e mesmo das culturas nele existentes, bem como do entendimento das relações de expansão capitalista.

Portanto, segundo Braudel (1995), o tempo histórico deve ser considerado em suas dimensões de "temporalidade" e "duração", compondo, portanto, a dialética da duração. Desta forma, pode-se compreender a estrutura para além de uma descrição linear de eventos ao longo do tempo, sendo este o mérito da análise geo-histórica, pois, segundo o autor, este pauta-se na capacidade em articular de forma sistémica as análises considerando o meio, a cultura e a sociedade.

Tecer uma análise tendo como base fundamental a história descrita na literatura regionalista bem como em textos científicos e de cunho geográfico da época anterior à institucionalização da geografia no Amazonas, onde se evidenciam os dilemas e desafios enfrentados por quem ocupava a imensidão verde, fossem nativos ou não da região amazônica, colabora de forma significativa para compreender a produção do espaço no Amazonas e como essas dinâmicas influenciaram a construção do método geográfico do Amazonas.

\section{A LITERATURA REGIONALISTA E SUAS CONTRIBUIÇÕES A EPISTEMOLOGIA DA GEOGRAFIA NO AMAZONAS}

Definir a gênese de um pensamento geográfico do Amazonas não nos parece ser uma tarefa fácil dada a complexidade das relações existentes na Amazônia, que a nosso ver, fundamentaram as bases desta ciência na região, sobretudo através de textos literários, científicos e descritivos sobre a imensidão verde.

Os registros dos pensadores, poetas, pesquisadores e viajantes que se debruçaram a investigar e compreender a Amazônia, a saber, Alberto Rangel (2017 [1908]), Betty J. Meggers (1987), Djalma Batista (2007 [1976]), Darcy Ribeiro (1995; 2001 [1968]), Euclides da Cunha (2006 [1909]), Henry Walter Bates (2004 [1863]), Johann B. V. Spix e Carl F. P. Martius (1981 [1823]), Leandro Tocantins (1968), Márcio Souza (2003 [1978]), Raymundo Moraes (1936), entre outros, ajudam a elucidar a dimensão dos processos físicos, políticos e sociais, existente na região entre os séculos XVIII e XIX, evidenciando a importância desses acontecimentos para história da evolução de um pensar geográfico no Amazonas.

Parece-nos pertinente dizer que as bases epistemológicas desse pensamento geográfico do Amazonas tem sua materialidade nos registros aqui analisados, uma vez que estes passam por minuciosa descrição da natureza, dos aspectos únicos da cobertura vegetal, das formações geológicas, das feições dos rios, bem como da identificação de uma unidade étnica, de movimentos migratórios e de sua ligação com as transformações econômicas, tratando ainda das relações entre estes, entre homem e meio, como sendo resultado de três forças diversificadoras e distintas classificadas por Ribeiro (1995) como sendo a ecológica, a econômica e a migratória.

Desta forma, entendemos que a sistematização da Geografia, enquanto ciência no Amazonas se deu principalmente com base nestas narrativas, valendo-se primeiro do conhecimento empírico aliado a

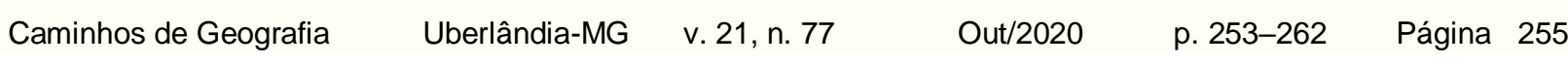


conhecimentos técnicos dos que viveram, passaram pela região e/ou atuaram de forma viril nas questões da Amazônia e do Amazonas, defendendo uma integração regional que não desprezasse a importância da natureza nas relações entre homem e meio, entre a população amazônida e a floresta, sendo esta necessária ao desenvolvimento pleno e efetivo, não só da região como também do povo já consolidado em terras amazônicas (SOUZA, 2003; BATISTA, 2007).

De grande importância para a presente análise foram os registros de Euclides da Cunha (2006), que apesar de não ser geógrafo de formação, contribuiu significativamente para o estabelecimento da ciência geográfica não somente no Amazonas, como também no Brasil. Suas narrativas ultrapassam as barreiras do tempo e ainda hoje se mostram incrivelmente autênticas e atuais, sobretudo os trechos em que trata da relação entre a sociedade e a natureza observados na Amazônia, da dinâmica fluvial, do ciclo hidrológico e pluviométrico regional bem como de aspectos do clima como fatores importantes para o desenvolver da precária e penosa vida amazônica.

As considerações de Euclides da Cunha a respeito do clima peculiar e único da Amazônia se fazem presentes também em cartas enviadas a parentes e amigos, logo após sua passagem por Belém e chegada a Manaus, onde o clima o fez passar por uma "experiência dolorosa que neste instante [...] me revela as exigências excepcionalíssimas de uma aclimação difícil [...] achei o traço essencial deste portentoso habitat' (CUNHA, 1905, apud BRAGA, 2002, p. 133).

O trabalho produzido enquanto chefe da missão exploratória do Alto Purus, publicado postumamente no livro A Margem da História em seu capítulo I, Amazônia: terra sem história evidencia a importante relação homem/natureza que a nosso ver, fundamentam a sistematização de um pensar/fazer da Geografia no Amazonas.

Ao relatar os dilemas enfrentados pelos extrativistas do período da borracha Euclides da Cunha confronta a ideologia de homem preguiçoso e tido como empecilho aos interesses da colônia, propondo um pensamento diferente, colocando que o nativo que se dispunha a este serviço "é o homem que trabalha para escravizar-se" (CUNHA, 2006, p. 28). Ao chegar à Amazônia e deparar-se com a realidade, o estrangeiro sofria com as distâncias e o clima local, devendo assim reconhecer o homem amazônida como ser forte, frente ao desafio de habitar a Amazônia. "Aquele tipo de lutador é excepcional [...] e quase sempre adoece, a mercê da incontinência generalizada" (CUNHA, 2006, p. 30).

As relações comerciais existentes na Amazônia do século XVIII e início do século XIX induziram a uma exploração não só dos recursos da floresta, como também da mão de obra dos nativos, que tiveram seus conhecimentos renegados pelos conquistadores europeus e este fato, associado ao descaso com os trabalhadores, são duramente criticados nos relatos da época, sobretudo por Márcio Souza (2003) e Euclides da Cunha (2006), que apontam para uma exploração desumana do trabalhador do extrativismo amazônico.

Observamos ainda que as críticas ao modo como o homem amazônico é visto por quem é externo a realidade local, um ser preguiçoso e sem perspectiva de ascensão socioeconômica (SOUZA, 2003), são recorrentes nos relatos sobre as inúmeras tentativas desenvolvimento regional, sendo a época o discurso usado como justificativa para a vinda de trabalhadores de outras regiões, como os Nordestinos nos tempos áureos da borracha, para suprir a demanda por mão de obra, visto a difícil relação com os povos nativos da região, que perdurava desde as primeiras incursões a Amazônia.

Outro autor foi Djalma Batista, o qual figura entre os grandes pesquisadores que buscaram a compreensão das questões amazônicas, tendo como principais contribuições as críticas ao modo irracional de exploração das riquezas e do povo amazônico, elencando diversas possíveis saídas para as históricas questões do Amazonas.

Há que se registrar também as importantes contribuições dos chamados naturalistas para o arcabouço de conhecimentos que se construiu sobre a Amazônia e o Amazonas, destacando os trabalhos de Walter Bates (2004 [1863]) intitulado The 256uropeia256ta on the river Amazons, e dos pesquisadores Spix e Martius (1981) intitulado Viagem pelo Brasil, onde fazem minuciosas descrições sobre o Rio Amazonas e seus tributários, bem como o da pesquisadora Betty J. Meggers (1987) que em sua obra, Amazônia: A ilusão de um paraíso, propõe uma análise das condições de exploração dos recursos na Amazônia, tendo o rio como um significativo elemento, seja da ótica em que este assume papel importante para a economia regional como também, sendo o grande prejudicado pela intensificação da exploração dos recursos da floresta.

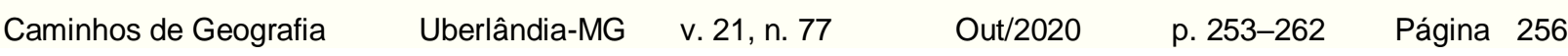


Os discursos e debates acerca dos processos de apropriação do território no Amazonas propostos nos textos analisados nos indicam uma preocupação com a forma de construção étnica local, bem como dos processos de urbanização, desenvolvimento e da implantação de modelos econômicos, que perduram da Colônia à República, induzindo a transformações políticas, sociais e econômicas (TRINDADE JR., 2016), constituindo-se como elo entre o observável e o palpável da Amazônia, contribuindo para a apreensão geográfica dos processos físicos e sociais, contudo, através de uma perspectiva da matriz filosófica positivista, ou seja, tendo como verdade o visível, o perceptível, o material, considerando a aparência dos fenômenos e a interdependência existente entre homem e meio, que resultam no espaço produzido. Esta é, portanto, a característica mais evidente nos estudos e relatos sobre a Amazônia analisados e que precedem a institucionalização da Geografia no Amazonas.

\section{TEMPO E ESPAÇO NA REGIÃO: DA RIQUEZA AO DECLÍNIO ECONÔMICO}

A Amazônia possui diversa literatura que evidenciam as transformações político/territoriais, étnicas, econômicas, sociais, ocorridas em diferentes tempos por todo espaço, porém, sempre tendo como principal agente motor a cobiça desmedida por suas riquezas naturais de grande valor no mercado internacional. Os "ciclos" de mudanças pelos quais a região passou sempre exigiram uma capacidade de ressignificação por parte da população que ocupava o incoercível maciço verde, e sofria com os desmandos dos detentores do poder e com a imposição de sistemas políticos e econômicos à região.

Dominar a imensidão amazônica era mais que uma questão de honra para a corte portuguesa e sim uma necessidade, haja vista a grande dependência econômica que a coroa tinha dos recursos extraídos da floresta, fato este que se evidenciou com a exploração indiscriminada das chamadas "Drogas do Sertão" e mesmo depois com a descoberta, exploração e comercialização do látex que fora o grande promotor da corrida capitalista na Amazônia, sobretudo na segunda metade do século XIX (ANTONIO FILHO, 2010).

No entanto, o promissor mercado da borracha amazônica teve um ciclo de vida extremamente curto, perdendo espaço no mercado internacional para a o produto extraído no continente asiático, o que trouxe consequências devastadoras para a economia regional e consequentemente para o Brasil, tendo como principais causas a queda no valor do produto no mercado internacional além da "desestruturação do sistema de exploração de mão de obra, implantado pelos missionários religiosos, que criou uma situação de estagnação econômica na região" (ANTONIO FILHO, 2010, p. 189).

Observou-se a substituição das especiarias da floresta pela extração e comercialização do látex, principalmente no fim do século XVIII e início do século XIX, importantíssimo para as atividades industriais na Europa, passando a ser o principal item comercial da colônia. Contudo, a concentração das atividades econômicas da região sobre um único produto fez com que a economia regional sofresse constantemente com os períodos entre a descoberta ou maior intensificação da exploração de certos produtos naturais, até a substituição deste por outro, como ocorreu com as "Drogas do Sertão" e posteriormente com seiva da seringueira, por exemplo, passando por períodos de auge, declínio, e estagnação.

A partir da década de 1920 o Brasil passa por consideráveis mudanças no tocante ao planejamento e a elaboração de estratégias que objetivavam o desenvolvimento pleno da economia nacional. É nessa perspectiva que a Amazônia ganha importância crucial para as estratégias engendradas pelo estado, tanto pela busca por ocupar e consolidar definitivamente a imensidão verde ao território brasileiro, bem como em relação à exploração dos recursos naturais, que passam a ter importância crucial para as ambições nacionalistas. O tempo amazônico é lento, portanto, pela objetiva de quem é externo a região, é estranho, o que pode explicar os modelos econômicos e de colonização pensados para esta porção do país.

Nas décadas subsequentes e, sobretudo a partir da década de 1940, o imaginário amazônico está intimamente ligado à ideia de um espaço para extração de recursos naturais como insumo para o progresso, evidenciando sua importância estratégica e justificando assim as empreitadas em direção ao desconhecido amazônico.

Torna-se grande desafio, fazer desta porção do território, parte do todo nacional, considerando suas distâncias dos grandes centros do país, tanto em escala geográfica quanto em escala econômica, barreira até então intransponível. 
A partir da década de 1950, com o movimento desenvolvimentista latente no país, há a intensificação do processo de industrialização idealizado e promovido pelo Estado, e que no Brasil, ocorre de maneira lenta e através de um processo exógeno (SANTOS, 2013). A partir deste período observa-se a intensificação da urbanização na Amazônia, sobretudo nas cidades de Manaus-AM e Belém-PA.

Neste contexto, o discurso ou defesa do Amazonas buscando situá-lo como espaço para desenvolvimento econômico, por meio da exploração dos recursos naturais, tem como maior entusiasta Djalma Batista, defensor da "habitabilidade do Amazonas" tendo como agente central e de crucial importância para este processo o próprio povo amazonense (ITUASSÚ, 1996).

É nesse contexto de afirmação da Amazônia, e mais precisamente do Amazonas, que se idealiza a implantação do Polo Industrial de Manaus (PIM) como objeto de ressignificação do uso dos recursos da floresta para impulsionar a economia regional, tornando-se evidência do interesse político que estavam intimamente ligados ao desejo de manter o monopólio das riquezas amazônicas, fossem elas já conhecidas ou não (LIMA, 2011).

Entende-se assim que as mudanças pelas quais a região passou são decorrentes de períodos históricos, com temporalidades e espacialidades singulares, como tudo na Amazônia, e que vai desde a exploração de forma desmedida dos recursos da floresta, por aqueles que chegaram à região reivindicando suas riquezas, grandes porções de terras, imprimindo culturas estranhas a terra e aos povos nativos, passando pelo auge e declínio da borracha e chegando a contemporaneidade, com o período de fomento do desenvolvimento regional e a promoção de políticas desenvolvimentistas, sob a égide do mote "ocupar para não entregar".

Por esta ótica, podemos apreender a Amazônia como um complexo de ações e relações sociais, econômicas e territoriais, através de processos de construção, desconstrução e reconstrução de paradigmas idealizados do império à república, viabilizando novas dinâmicas locais, sem, é claro, extinguir antigas práticas de exclusão que se perpetuam.

\section{DA DESCRIÇÃO DA NATUREZA À LEITURA DA PRODUÇÃO DO ESPAÇO: O PENSAMENTO GEOGRÁFIÇO NO AMAZONAS}

As contribuições ao savoir faire geográfico no Amazonas, não se restringem tão somente aos escritos até aqui mencionados, e por mais valiosos que sejam os trabalhos de Alberto Rangel, Djalma Batista, Euclides da Cunha, Márcio Souza, que buscaram desvendar a Amazônia dos séculos XVIII e XIX, e ainda assim, não esgotaram as possibilidades para se pensar as temporalidades e espacialidades das práticas políticas, sociais, culturais e capitalistas na floresta, mas que se constituem no alicerce da construção das abordagens, conceitos e métodos da Geografia no Amazonas, passando de análises descritivas marcadas pelo empirismo e naturalismo a uma interpretação e leitura da produção do espaço do/no Amazonas com os cientistas, pesquisadores e pensadores contemporâneos.

Para os europeus, a Amazônia nada mais era do que um espaço possível ao negócio, o que se intensificou com o mercado da borracha, e que tornou o homem amazônico ainda mais refém do recém-chegado modo de produção capitalista, que o explorava, matava e que o privou por longos períodos da vida em sociedade (CUNHA, 2006).

No Amazonas esta intensificação do modo de reprodução capitalista se refletiu no aumento de áreas urbanizadas, aumento do desmatamento e da exploração de recursos da floresta, emergindo novos símbolos na paisagem e assim

cercada pela selva, Manaus institucionalizou o isolamento como um preciso aspecto ornamental, tomando tudo por uma linguagem insólita e estéril, pela qual gerações inteiras viveram e morreram encarceradas. Manaus: o aglomerado urbano que emudeceu no centro do choque cultural mais fantástico que o Brasil já assistiu (SOUZA, 2003, p. 28).

Ainda sobre Manaus, chamada por Euclides da Cunha de "capital dos seringueiros", em carta ao amigo da Academia Brasileira de Letras, Domício da Gama, registra-se o descontentamento deste com a estrutura da cidade e com o cotidiano da dinâmica local, que o deixam extremamente irritado, Euclides desabafa dizendo que Manaus é

uma grande cidade estritamente comercial de aviadores solertes, zangões vertiginosos e ingleses de sapatos brancos. Comercial e insuportável [uma] cidade meio caipira, meio 258uropeia, onde o tejupar se achata ao lado de palácios e o cosmopolitismo exagerado põe ao lado do yankee espigado... o seringueiro achamboado, a impressão que ela nos incute é a de uma maloca transformada em Grand (CUNHA, 1905, apud BRAGA, p. 43). 
Autores ainda contemporâneos como Aziz Nacib Ab'Sáber através de estudos sobre a cidade de Manaus e Raymundo Moraes com seus trabalhos sobre a dinâmica fluvial da Amazônia, na década de 1950, despontaram como alguns dos grandes nomes da Geografia brasileira do século XX, tendo contribuído em muito para a sistematização tratada neste trabalho.

Se por um lado, conhecer a formação étnica da Amazônia tornar-se-ia até então um dos grandes desafios para os Antropólogos imbricados a desbravar e estudar a região entre os séculos XVII e XX, para os Geógrafos este desafio pautava-se em evidenciar como as relações entre homem/meio influenciaram na formatação do espaço, implantação das cidades e de infraestruturas, impulsionadas pelas relações comerciais e pela produção industrial da época (AB'SABER, 1953).

Os estudos sobre o relevo, da composição e características da cobertura vegetal, do clima além das observações da produção das cidades amazônicas, buscavam compreender os processos de mudanças pela qual a paisagem passava, vinculando-os ao surgimento de novos modos de produção industrial, tratando ainda sobre a importância de se investigar e, a partir de então, buscar alternativas em que a natureza e o homem pudessem coexistir de forma harmônica, valendo-se é claro de dados históricos e científicos já sistematizados por seus predecessores.

Ab'Saber (1952; 1953) argumenta que a constituição de Manaus, próximo a confluência dos rios Negro e Solimões, evidencia a importância que a cidade teve para o comércio do estado do Amazonas a época de sua implantação. A possibilidade de ligação com as porções Oeste, Noroeste e Sudoeste da Amazônia ocidental fez da capital do Amazonas ponto crucial para o desenvolvimento regional, tornando possível compreensão das motivações que levaram a sua consolidação em tal localização geográfica.

Para Monteiro (2012) Manaus implantou-se como entreposto para o comércio internacional das especiarias amazônicas, desta forma "o fenômeno da ocupação do solo, na raia do atual município de Manaus, demorou de longos anos a aparecer como uma nítida feição da política econômica primária portuguesa" (MONTEIRO, 2012, p. 21).

Assim, evidencia-se como a produção do espaço no Amazonas, sobretudo da cidade de Manaus, estava intimamente ligada ao desenvolvimento das técnicas da época e presa a uma logística de transporte e mobilidade da época, uma vez que "alí o aglomerado urbano, por mais de dois séculos, não dependeu de nenhuma rota terrestre, mas tão somente dos rios de planície e de uma história econômica ligada intimamente a navegação fluvial" (AB'SÁBER, 1953, p. 19).

Os conflitos inerentes a essa dinâmica, capital/sociedade/natureza, evidenciam-se na medida em que as ocupações na Amazônia acontecem sem o planejamento adequado, resultando em espaços urbanos onde se multiplicam os problemas, sobretudo os relacionados a moradia e a questões ambientais.

Estes primeiros estudos, feitos por Ab'saber, Raymundo Moraes, Mário Ypiranga Monteiro, sobre Manaus, levando em consideração a formação do núcleo urbano e suas relações com a natureza tornam-se um marco da mudança de paradigmas do pensamento geográfico que passou a se construir no Amazonas, haja vista que, posteriormente, na década de 1980 é criado o primeiro curso de formação superior no estado do Amazonas, cerca de meio século depois da institucionalização dos cursos de Geografia no Rio de Janeiro e em São Paulo, respectivamente.

A obra de Euclides da Cunha (2006), retratando a Amazônia como "terra sem história", e que data de 1909, bem como Alberto Rangel (2017), com sua representação da Amazônia como "Inferno Verde", com sua primeira edição lançada em 1908, são, a nosso ver, ponto de partida para a Geografia no Amazonas, ricos não somente no que se refere as descrições da natureza e de seus aspectos físicos, das formações dos rios e das particularidades do clima regional, expressando ainda, em suas entrelinhas, as primeiras análises de cunho geográfico sobre a região.

Os desdobramentos e as construções teórico-metodológicas da Geografia no período analisado, desencadearam diversos estudos sobre a região amazônica, ainda que tendo traços da uma ciência quantitativista, sendo posteriormente, em meados do século $X X$, repensada sob o viés crítico, métodos e abordagens, movimento chamado de Geografia Crítica, pautada na prática geográfica dotada de forca e materialidade para fazer críticas não só a sociedade como também ao modo de produção capitalista, abordando o espaço e suas formas de apropriação da natureza (LACOSTE, 2017 [1929]). 
Destarte, as mudanças pelas quais a Geografia passou se materializam nas respostas trazidas através dos resultados das pesquisas e que evidenciam as nuances do que foi um dia e do que se constitui hoje. Sendo assim, a correlação entre os primeiros escritos de cunho geográfico sobre o Amazonas com as análises feitas posteriormente, já dotadas de um método próprio da Geografia, considerando a indissociável relação entre as ações antrópicas sobre o meio bem como a relação entre eles (homem/meio), sempre conflituosa e complexa, para explicar o espaço construído, produzido, torna-se a materialização da evolução de um saber fazer da geografia no Amazonas, que não se vê mais embasada tão somente em análises descritivas e puramente empíricas, como também em estudos concretos sobre a formatação do espaço geográfico como objeto de estudo.

\section{CONSIDERAÇÕES FINAIS}

Várias perguntas nos motivaram a refletir o trajeto deste texto, dentre elas algumas nos acompanharam durante todo o percurso da pesquisa. Por exemplo, estaríamos buscando uma história da geografia ou uma geografia histórica do Amazonas? E independente da resposta para este primeiro questionamento, como as descrições sobre a Amazônia e o Amazonas poderiam traçar um panorama para uma Geografia do Amazonas?

A Amazônia desde a chegada dos exploradores tem sido marcada por conflitos e disputas entre os que reivindicavam a posse de seu território, de suas riquezas e domínio sobre o povo que ocupava a vasta região. Como consequência desse choque entre povos e culturas distintas tem-se hoje uma população miscigenada e de cultura plural que se constitui como elo entre sociedade e natureza e de sua interdependência, crucial para a compreensão do espaço como organismo dinâmico.

Sabemos que a Geografia passou por diversas mudanças teórico-metodológicas até estabelecer-se como ciência, o que só veio a se concretizar no século XIX, tendo como grandes influenciadoras as escolas Francesa e Alemã, representadas pelos trabalhos de renomados pesquisadores como Alexander Von Humboldt e de Karl Ritter, que contribuíram para afirmação como ciência, pautada em método e abordagem própria, clássica, fazendo uso da razão para explicar o espaço, marcando a ruptura com os mitos, crenças e superstições, e mantendo forte relação com o meio físico, a natureza.

Consideramos, portanto, ser este o perfil dos escritos aqui analisados, tendo como base suas experiências, vivências e observações, capitadas nas diversas passagens pela região amazônica nos séculos XVIII e XIX, tendo por influência um recorte espaço/temporal particular. Desta forma, entendemos que os textos e autores, a partir dos quais as reflexões presentes neste trabalho foram concebidas, não foram voltados exclusivamente para o Amazonas, pelo contrário, influenciaram e inspiraram a geografia na Amazônia e até mesmo no Brasil. Ressalta-se, contudo que são fundamentais para compreender os estudos da geografia e seus temas no Amazonas.

Com as mudanças nas correntes de pensamento da Geografia emergem novas perspectivas que passaram a configurar não só a ampliação dos temas abordados pela ciência geográfica, como também a consolidação das formas de abordagens desta ciência. Estas são, portanto, as bases teórico-metodológicas da Geografia no Amazonas que, do positivismo à Geografia Crítica, passando da síntese de múltiplas ciências as relações de produção do espaço, constituem o savoir faire e o pensamento geográfico do Amazonas.

Apreende-se desta forma que o pensamento geográfico no Amazonas firmou-se incorporando os conceitos e sinônimos cristalizados na literatura regionalista que precede a Geografia enquanto ciência, tendo como principal ferramenta a paisagem, o bucólico, o incoercível da floresta, que disseminou a ideia de uma Amazônia do natural, do verde, da diversidade bioecológica, que fora importantíssima para pensar, inclusive, em uma Geografia Clássica do Amazonas, empírica, descritiva, não científica ainda, apenas um fazer geográfico marcado por descrições do homem e do seu meio, partindo do inferno verde e chegando ao complexo do Amazonas.

\section{AGRADECIMENTOS}

Ao Conselho Nacional de Desenvolvimento Científico e Tecnológico/CNPq pelo apoio financeiro e ao Núcleo de Pesquisas Urbana e Regional/Npur/CNPq da Universidade do Estado do Amazonas/UEA, espaços de desenvolvimento da pesquisa.

\begin{tabular}{|c|c|}
\hline & Uberlândia-MG \\
\hline
\end{tabular}




\section{REFERÊNCIAS}

AB'SÁBER, A. N. Na região de Manaus. Fotografias e comentários. Boletim Paulista de Geografia, São Paulo, n. 14, p. 55-66, 1952.

p. $18-45,1953$

A cidade de Manaus: primeiros estudos. Boletim Paulista de Geografia, São Paulo, n. 15,

ANTONIO FILHO, F. D. Na planície Amazônica, de Raymundo Moraes: uma avaliação do pensamento geográfico na literatura regionalista. In: VITTE, A. C. (org) Contribuições à história e à epistemologia da geografia. Rio de Janeiro: Bertrand Brasil, 2007 (p.217-251).

Riqueza e miséria do ciclo da borracha na Amazônia brasileira: um olhar geográfico por intermédio de Euclides da Cunha. In: GODOY, Paulo R. Teixeira de (org.) História do pensamento geográfico e epistemologia em Geografia. São Paulo: Cultura Acadêmica, Editora Unesp, 2010 (p.187-207).

BATES, Henry Walter. The naturalist on the river Amazons. London: Routledge, 2014.

BATISTA, Djalma. O complexo da Amazônia: análise dos processos de desenvolvimento. $2^{\mathrm{a}}$ ed. Manaus: Editora Valer, Edua e INPA, 2007.

BRAGA, Robério. Euclides da cunha no Amazonas. Manaus: Editora Valer/Fundação Lourenço Braga, 2002.

BRAUDEL, Fernand. O mediterrâneo e o mundo mediterrâneo na época de Felipe II. $2^{\underline{a}}$ edição. Lisboa: Publicações Dom Quixote, 1995.

CUNHA, Euclides da. À margem da história. Coleção Obra prima de cada autor. São Paulo: Martin Claret, 2006.

Amazônia, um paraíso perdido. Manaus: Valer, 2011.

ITUASSÚ, Oyama. Djalma Batista - um homem de cultura. In SERÁFICO, José (org.) Djalma Batista: um humanista da Amazônia. Manaus: Editora da Universidade do Amazonas, 1996, p. 17-28.

LACOSTE, Yves. A Geografia - isso serve, em primeiro lugar, para fazer a guerra. 19a ed. Campinas: Papirus, 2012.

MEGGERS, Betty J. Amazônia. A ilusão de um paraíso. Belo Horizonte: Itatiaia; São Paulo: Editora da Universidade de São Paulo, 1987.

MELO, Susane Patrícia Melo de et al. Uma análise multiescalar da problemática urbana em Manaus: apontamentos para a sustentabilidade da cidade. Revista GEONORTE, [S.I.], v. 2, n. 2, p. 35 - 56, dez. 2011. ISSN 2237-1419. Disponível em: <http://www.periodicos.ufam.edu.br/revistageonorte/article/view/1121>. Acesso em: 22 mar. 2019.

MONTEIRO, Mário Ypiranga. Fundação de Manaus. 5 $5^{\mathrm{a}}$ Ed. Manaus: Governo do Estado do Amazonas - Secretaria de Cultura, 2012.

MORAES, A. C. R. Geografia: pequena história crítica. 19ª ed. São Paulo: Annablume, 2003.

MORAES, Raymundo. Na planície amazônica. Brasil: Editora Nacional, 1936.

RANGEL, Alberto. Inferno verde: cenas e cenários do Amazonas. Brasília, DF: Projeto E-Livros, 2017.

RIBEIRO, Darcy. O povo brasileiro: a formação e o sentido do Brasil. São Paulo: Companhia das Letras, 1995. Letras, 2001.

O processo civilizatório: etapas da evolução sociocultural. São Paulo: Companhia das

RIBEIRO, Guilherme. A arte de conjugar tempo e espaço: Fernand Braudel, a geo-história e a longa duração. História, Ciências, Saúde, Manguinhos, Rio de Janeiro, v.22, n.2, abr.-jun. 2015, p. 605-639. https://doi.org/10.1590/S0104-59702015000200008

SANTOS, Milton. A urbanização brasileira. São Paulo: Edusp, 2013.

SOUZA, Márcio. A expressão amazonense: do colonialismos ao neocolonialismo. Manaus: Editora Valer, 2003. 
SPIX, J. B. V. MARTIUS, C. F. P. Viagem pelo Brasil: 1817 - 1820. v. 3/3. Belo Horizonte: Ed. Italiana; São Paulo: Editora da Universidade de São Paulo, 1981.

TRINDADE JR., S-C. C. A Amazônia e o pensamento geográfico brasileiro: uma leitura a partir da escola uspiana de geografia in VITTE, A. C. (org) Contribuições à história e à epistemologia da geografia. Rio de Janeiro: Bertrand Brasil, 2007, p. 355-364.

TOCANTINS, Leandro. O Rio comanda a vida - uma interpretação da Amazônia. Rio de Janeiro: Record, 1968.

Recebido em: 24/05/2019

Aceito para publicação em: 17/09/2020 